\title{
STUDY OF VITAMIN D LEVELS IN POSTMENOPAUSAL WOMEN
}

Arshiya Begum Azmathullah1, Selvapandian Kirubharan², Latha Jeyasubramanian³, Priya Anbarasan4, Vanitha Kandasamy5, Santhi Natesan 6 , Sathiya Kandasamy ${ }^{7}$, Chandrakala Karupasamy ${ }^{8}$

1 Professor, Department of Biochemistry, KAPV Govt. Medical College, Trichy, Tamil Nadu Dr. MGR Medical University, Chennai. 2Professor, Department of Biochemistry, Dhanalakshmi Srinivasan Medical College, Perambalur, Tamil Nadu Dr. MGR Medical University, Chennai.

${ }^{3}$ Tutor, Department of Biochemistry, KAPV Govt. Medical College, Trichy, Tamil Nadu Dr. MGR Medical University, Chennai.

${ }_{4}^{4}$ Tutor, Department of Biochemistry, KAPV Govt. Medical College, Trichy, Tamil Nadu Dr. MGR Medical University, Chennai.

${ }^{5}$ Assistant Professor, Department of Biochemistry, KAPV Govt. Medical College, Trichy, Tamil Nadu Dr. MGR Medical University, Chennai. ${ }^{6}$ Assistant Professor, Department of Biochemistry, KAPV Govt. Medical College, Trichy, Tamil Nadu Dr. MGR. Medical University, Chennai.

7Postgraduate, Department of Biochemistry, KAPV Govt. Medical College, Trichy, Tamil Nadu Dr. MGR Medical University, Chennai. 8Postgraduate, Department of Biochemistry, KAPV Govt. Medical College, Trichy, Tamil Nadu Dr. MGR Medical University, Chennai.

\section{ABSTRACT}

\section{BACKGROUND}

There is an alarming increase in the prevalence of vitamin D deficiency in elderly women in South India. Low vitamin D status is associated with an increased risk of osteoporosis and a variety of other health outcomes that requires urgent attention.

\section{AIMS AND OBJECTIVES}

To evaluate the levels of vitamin D in postmenopausal women in South Indian population and to determine the correlation of serum vitamin D levels with serum levels of alkaline phosphatase.

\section{MATERIALS AND METHODS}

This population-based cross-sectional study was done in 52 postmenopausal women. Vitamin D was estimated by Chemiluminescent Immunoassay (C.L.I.A.) statistical analysis was done using SPSS version 21 software.

\section{RESULTS}

The descriptive statistics of the study group are given as mean \pm standard deviation and the p-value is also given. The mean age of the study population is $68.42 \pm 6.96$. The mean levels of vitamin $D$ is $13.81 \pm 5.26$. The mean levels of serum alkaline phosphatase is $128.27 \pm 29.53 \mathrm{U} / \mathrm{L}$. Out of 52 samples, none $(0 \%)$ of the postmenopausal women had optimal levels of vitamin $\mathrm{D}, 43(82 \%)$ were in the insufficient range, and $9(17 \%)$ were in the deficient range. All of the patients in both insufficient and deficient groups had normal levels of serum alkaline phosphatase.

\section{CONCLUSION}

There is high prevalence of vitamin D deficiency in healthy postmenopausal women and there is no correlation of serum vitamin D levels with serum levels of alkaline phosphatase.

\section{KEYWORDS}

Postmenopausal Women, Vitamin D, Alkaline Phosphatase.

HOW TO CITE THIS ARTICLE: Azmathullah AB, Kirubharan S, Jeyasubramanian L, et al. Study of vitamin d levels in postmenopausal women. J. Evolution Med. Dent. Sci. 2016;5(66):4740-4744, DOI: 10.14260/jemds/2016/1080

\section{INTRODUCTION}

The D vitamins are a group of sterols that have a hormonelike function. The active molecule, 1,25-dihydroxy cholecalciferol binds to intracellular receptor proteins. The D3-receptor complex interacts with DNA in the nucleus of target cells in a manner similar to that of vitamin A and either selectively stimulates gene expression or specifically represses gene transcription.

The most prominent actions of 1,25dihydroxycholecalciferol are to regulate the plasma levels of calcium and phosphorus.

Financial or Other, Competing Interest: None.

Submission 04-07-2016, Peer Review 05-08-2016,

Acceptance 11-08-2016, Published 18-08-2016.

Corresponding Author:

Dr. Arshiya Begum Azmathullah,

Door No. 16. Asif Manzil,

Khaja Nagar, Trichy-620020.

E-mail: arshiyavasi@gmail.com

DOI: $10.14260 /$ jemds $/ 2016 / 1080$ 7-dehydrocholesterol, an intermediate in cholesterol synthesis is converted to cholecalciferol in the dermis and epidermis of humans exposed to sunlight. Preformed vitamin $\mathrm{D}$ is a dietary requirement only in individuals with limited exposure to sunlight. When human skin is exposed to sunlight, it is the solar ultraviolet B photons with energies between 290 and $315 \mathrm{~nm}$ that are responsible for causing the photolysis of 7-dehydrocholesterol. This photochemical process occurs in the plasma membrane of skin cells; as a result, the thermodynamically unstable cis, cis isomer of previtamin D3 is rapidly transformed by a rearrangement of double bonds to form vitamin D3.[1] Approximately, 50\% of previtamin D3 is converted to vitamin D3 within 2 hours. Once vitamin D3 enters the extracellular fluid space, it is attracted to the vitamin D binding protein in the circulation, and thus enters the dermal capillary bed.[2] The vitamins D2 and D3 are not biologically active, but are converted in vivo to the active form of the $\mathrm{D}$ vitamin by two sequential hydroxylation reactions. 
The first hydroxylation occurs at the 25-position and is catalysed by a specific hydroxylase in the liver. The product of the reaction, 25-hydroxycholecalciferol is the predominant form of vitamin $\mathrm{D}$ in the plasma and it is the major storage form of the vitamin D. 25-OH D3 is further hydroxylated at the one position by a specific 25-hydroxycholecalciferol.

1-hydroxylase found primarily in the kidney resulting in the formation of 1,25-dihydroxycholecalciferol. 1,25 dihydroxy D3 is the most potent vitamin D metabolite. Its formation is tightly regulated by the level of plasma phosphate and calcium ions. 25-hydroxycholecalciferol 1hydroxylase activity is increased directly by low plasma phosphate or indirectly by low plasma calcium, which triggers the release of parathyroid hormone.

Vitamin D occurs naturally in fatty fish, liver, and egg yolk. Milk is not a good source of the vitamin. But, milk and fat spreads are fortified with vitamin D.[3]

\section{EFFECTS OF VITAMIN D ON BONE}

Vitamin D is essential for maintaining calcium homeostasis and important in the maintenance of bone metabolism. ${ }^{[4]}$ 1,25-dihydroxy vitamin $\mathrm{D}$, which is the active vitamin $\mathrm{D}$ metabolite binds to a specific nuclear hormone receptor thereby increasing intestinal calcium absorption and regulating bone turnover. Low concentrations of vitamin D lead to alterations in calcium and phosphorus homeostasis, secondary hyperparathyroidism, bone loss, osteoporosis, and an increase in fracture risk. ${ }^{[5]}$ More severe degrees of vitamin D deficiency lead to impairment of bone mineralisation and osteomalacia.[6] Severe and prolonged vitamin D deficiency causes osteomalacia. Elderly postmenopausal females are most vulnerable for subclinical vitamin D deficiency.[7] Vitamin D deficiency leads to development of secondary hyperparathyroidism and bone loss and it is implicated in the pathogenesis of senile osteoporosis.[8] Dietary intake of calcium and phosphorus is shown to affect both bone mass and vitamin D metabolism.[9,10]

Vitamin D stimulates bone matrix formation and bone maturation. It also enhances osteoclastic activity and it influence differentiation of bone cell precursors.[11] Together with parathyroid hormone it regulates calcium and phosphorus metabolism and promotes calcium absorption from the gut and kidney tubules.[12] The fractional calcium absorption increases with serum vitamin D concentrations within the reference range up to a level of $80 \mathrm{nmol} / \mathrm{L}$.[13]

Researches show that mild vitamin D insufficiency can have a detrimental effect on bone mineral mass in adolescent females and children. Vitamin D deficiency typically presents with bony deformity (rickets) or hypocalcaemia in infants and childhood and with weakness and musculoskeletal pain in adults. Many other conditions such as cardiovascular disease, type 2 diabetes, cancers, and autoimmune conditions are associated with vitamin $\mathrm{D}$ insufficiency.

Risk factors for the development of vitamin D deficiency are increased skin pigmentation, application of sunscreen, which absorbs the UVB radiation, which leads to decreased penetration of UVB photons into the epidermis and reduced production of precholecalciferol, clothing also absorbs UVB radiation and lead to decreased synthesis of cholecalciferol, elderly or institutionalised, malabsorption, renal disease, liver disease, obese individuals, and persons on long-term use of anticonvulsants.[14]
Vitamin D insufficiency does not cause symptomatic muscle or bone disease. But, it is associated with increased risk of diseases such as cardiovascular disease, diabetes mellitus, carcinoma of bowel, carcinoma of breast, multiple sclerosis, and also increased risk of mortality.[15]

The elderly are often very concerned about their health and appearance and some will consistently apply a topical sunscreen on all sun-exposed areas and/or wear clothing over most sun-exposed areas before going outdoors. Since ageing significantly decreases the capacity of the skin to produce vitamin D3 because of the marked decline in 7 dehydrocholesterol in the epidermis, chronic sunscreen use by the elderly can increase the risk of vitamin D deficiency. Individuals with symptomatic osteomalacia or rickets have serum vitamin D concentrations of less than $10 \mathrm{ng} / \mathrm{mL}$, reflecting profound vitamin D deficiency.[16] When both the endogenous and exogenous sources are insufficient, vitamin D deficiency occurs, which contributes to a reduced bone mass in elderly women.

Risk fractures for osteoporosis are numerous. The menopause and other causes of hypogonadism in both women and men strongly predispose to osteoporosis. Various endocrinopathies especially glucocorticoid excess also are important. The contribution of family history may be explained by one or more genetic markers. Poor vitamin D and calcium nutrition, smoking, high alcohol consumption, and inactivity increase risk. Reduced bone mass is a major risk factor for fracture, although the magnitude of that risk may vary between populations. Additional factors that affect the fracture risk are bone fragility, length of the femoral neck (for hip fracture), history of prior fracture (for vertebral fracture) and falls.[17] Proximal muscle weakness and pain are the main symptoms of vitamin D deficiency in adults. Rib, hip, pelvis, thigh, and foot pain also occurs. More diffuse muscular aches and muscle weakness of the limbs and back are also common and combination of these symptoms are commonly called as "fibromyalgia" or somatisation of depression.

The skeletal system requires optimum development and maintenance of its integrity throughout its life cycle to prevent the occurrence of fractures. If the loads placed on the bone exceeds the ability of the bone to absorb the energy involved, then bones will break.[18] The number of factors which results in fractures include 1) reduction in bone mass, a change in the distribution of bone, 2) loss of cancellous or cortical microarchitecture, 3) accumulation of damaged bone, 4) a change in the matrix properties of the remaining bone.

The pathogenesis of osteoporosis is multifactorial. Both the development of peak bone mass and the rate of bone loss are determined by key endogenous and exogenous factors. In women early post menopause ( $<5$ years post menopause) who are not vitamin D deficient, Ca supplementation has little effect on bone mineral density. However, supplementation with vitamin $\mathrm{D}$ and Ca has been shown to reduce fracture rates in the institutionalised elderly, but there remains controversy as to whether supplementation is effective in reducing fracture in free living populations. Bone is a living tissue. There is a continuous cycle of active bone formation (through the activity of osteocytes and osteoblasts) and bone resorption (involving osteoclasts). Osteoclasts are attracted to a quiescent bone surface and then excavate an erosion cavity.[19] 
Mononuclear cells smooth off the erosion cavity, which is a subsequent site for the attraction of osteoblasts that synthesise an osteoid matrix. Continuous new bone matrix synthesis is followed by calcification of the newly-formed bone. When complete, lining cells once more overlie the trabecular surface.[20] Osteoporosis is defined as a metabolic bone disease 'characterised by low bone mass and microarchitectural deterioration of bone tissue leading to enhanced bone fragility and a consequent increase in fracture risk'.[21] Dual Energy X-ray Absorptiometry scanning (DEXA) shows low bone density, plain radiography reflect osteopenia or osteomalacia.[22]

The recommended daily intake of vitamin $\mathrm{D}$ for adults is $400 \mathrm{IU}(10 \mu \mathrm{g})$ per day, for children aged between 6 months and 3 years is $280 \mathrm{IU}(7 \mu \mathrm{g})$, and for infants under 6 months the allowance needed is $340 \mathrm{IU}(8.5 \mu \mathrm{g})$ per day.[23]

\section{RESULTS}

The descriptive statistics of the study group are given in Table- 1 as mean \pm standard deviation and the p-value is also given. The mean levels of vitamin $D$ in the age group of 60-69 is $12.8 \pm 1.75$. The mean levels of vitamin $D$ in the age group of $70-79$ is $15.5 \pm 6.5$. The mean age of the study population is $68.42 \pm 6.96$. The mean levels of vitamin $D$ is $13.81 \pm 5.26$. The mean levels of serum alkaline phosphatase is $128.27 \pm 29.53$ U/L. The study population was grouped into three based on the vitamin D levels those with optimal levels of vitamin D $>30 \mathrm{ng} / \mathrm{mL}$, those with vitamin D insufficiency $10-29 \mathrm{ng} / \mathrm{mL}$, those with vitamin D deficiency the level is $<10 \mathrm{ng} / \mathrm{mL}$. The mean levels of serum vitamin $D$ in insufficient group is $15.69 \pm 4.29$ and the mean levels of serum vitamin $D$ in the deficient group is $7.19 \pm 2.24$ is as shown in Table 2. The means of vitamin $D$ and alkaline phosphatase were compared using paired sample $\mathrm{T}$ test. Independent sample $\mathrm{T}$ test was used to compare when the participants were grouped by the vitamin D levels as optimal (>30 ng/mL), insufficient (10-29 $\mathrm{ng} / \mathrm{mL})$, and deficient $(<10 \mathrm{ng} / \mathrm{mL})$

Out of 52 samples, none $(0 \%)$ of the postmenopausal women had optimal levels of vitamin D, 41 (79\%) were in the insufficient range, and 11 (21\%) were in the deficient range. All of the patients in both insufficient and deficient groups had normal levels of serum alkaline phosphatase. There was no significant difference in the serum alkaline phosphatase levels between vitamin D insufficient and deficient persons. The mean levels of serum alkaline phosphatase in vitamin $D$ insufficient group is $127.55 \pm 27.72 \mathrm{U} / \mathrm{L}$ and the mean levels of serum alkaline phosphatase in vitamin $D$ deficient group is $128.46 \pm 30.32 \mathrm{U} / \mathrm{L}$ as shown in Table 3. Pearson correlation was applied to test the correlation of serum alkaline phosphatase levels with serum vitamin D levels. $P$ value $<0.05$ was considered to be significant. The correlation coefficient of alkaline phosphatase and serum vitamin D3 levels was $r=0.194$.

\begin{tabular}{|c|c|c|c|c|c|}
\hline & N & Min & Max & Mean & STD DEV \\
\hline Age & 52 & 65 & 79 & 68.42 & 6.9 \\
\hline Vitamin D & 52 & 4.2 & 25.4 & 13.89 & 5.2 \\
\hline ALP & 52 & 66 & 194 & 128.27 & 29.53 \\
\hline \multicolumn{6}{|c|}{ Table 1: Descriptive Statistics } \\
\hline
\end{tabular}

\begin{tabular}{|c|c|c|}
\hline & $\begin{array}{c}\text { VIT D } \\
(\text { Mean } \pm \text { SD })\end{array}$ & $\begin{array}{c}\text { Student } \\
\text { T Test }\end{array}$ \\
\hline $\begin{array}{c}\text { Insufficient } \mathrm{N}=41 \\
(10-29 \mathrm{ng} / \mathrm{mL})\end{array}$ & $15.69 \pm 4.29$ & \multirow{2}{*}{$<0.05$ (Significant) } \\
\hline $\begin{array}{c}\text { Deficient } \mathrm{N}=11 \\
(<10 \mathrm{ng} / \mathrm{mL})\end{array}$ & $7.19 \pm 2.24$ & \\
\hline Table 2: Com & $\begin{array}{l}\text { of Vitam } \\
\text { Populat }\end{array}$ & evels among the \\
\hline
\end{tabular}

\begin{tabular}{|c|c|c|c|}
\hline & $\begin{array}{c}\text { ALP } \\
\text { (Mean } \pm \text { SD) }\end{array}$ & $\begin{array}{c}\text { Pearson } \\
\text { Correlation }\end{array}$ & $\begin{array}{c}\text { Student } \\
\text { T Test }\end{array}$ \\
\hline $\begin{array}{c}\text { Insufficient } \\
\mathrm{N}=41(10-29 \\
\mathrm{ng} / \mathrm{mL})\end{array}$ & $127.55 \pm 27.72$ & & \\
& & $\mathrm{r}=0.91$ & $\begin{array}{c}\mathrm{P}=0.928 \\
\text { (Not } \\
\text { Significant) }\end{array}$ \\
$\begin{array}{c}\mathrm{N}=11(<10 \\
\mathrm{ng} / \mathrm{mL})\end{array}$ & $128.46 \pm 30.32$ & & \\
\hline \multicolumn{3}{|c|}{ Table 3: Comparison of Alkaline Phosphatase among } \\
Vitamin D Insufficient and Deficient Group
\end{tabular}

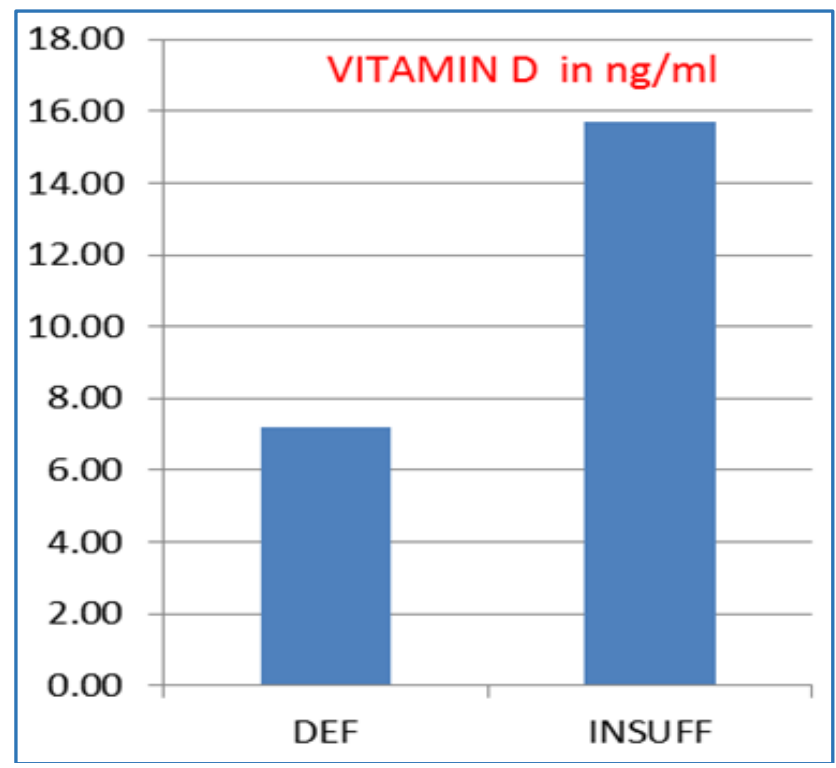

Fig. 1: Comparison of Vitamin D Levels among the Study Population

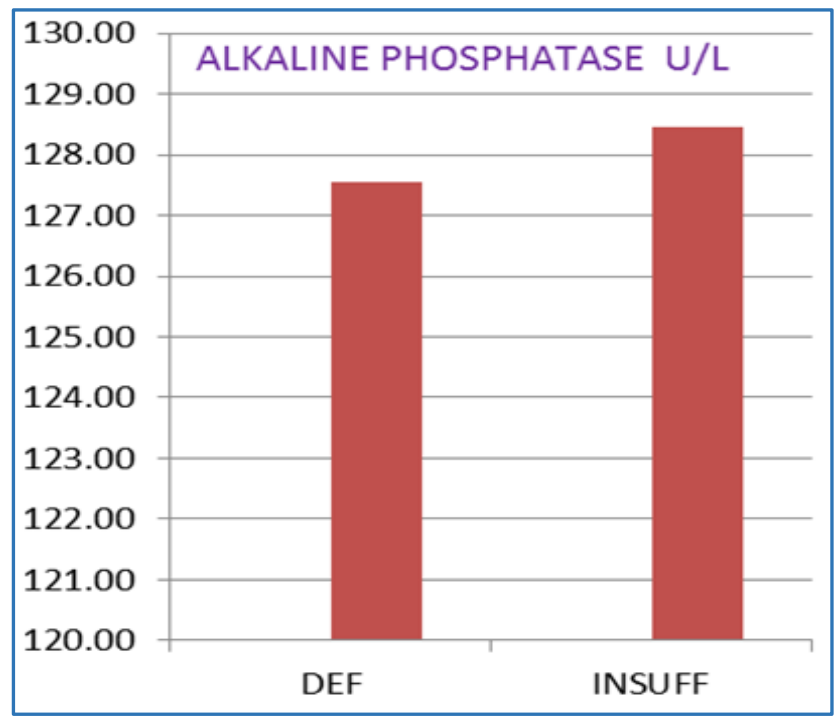

Fig. 2: Comparison of Alkaline Phosphatase among Vitamin D Insufficient and Deficient Group 


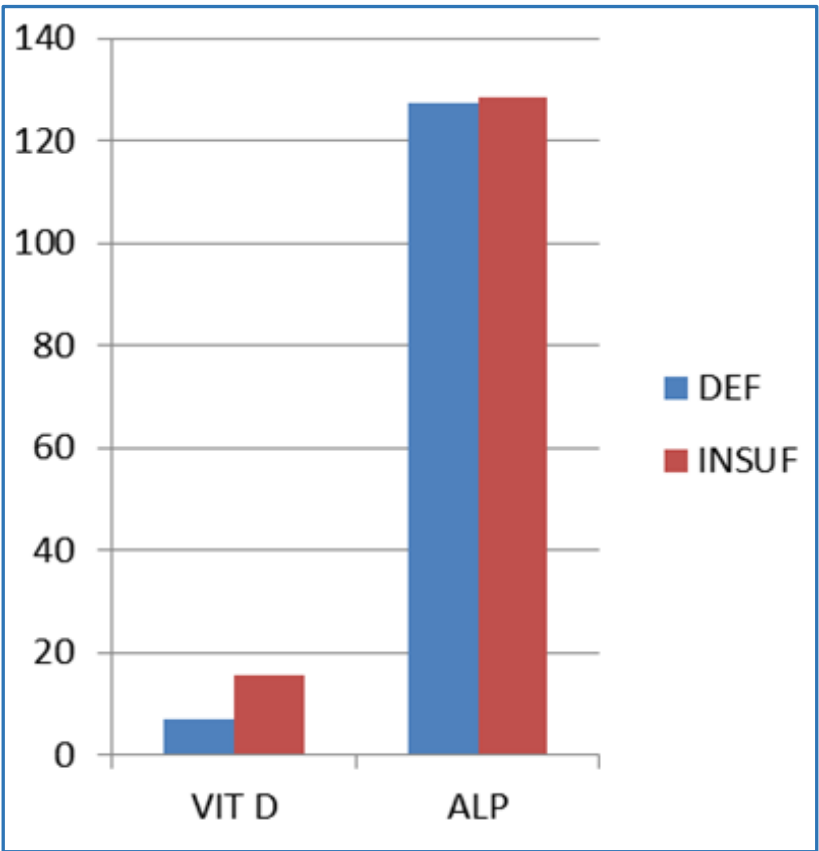

Fig. 3: Comparison of Vitamin D and Alkaline Phosphatase in Insufficient and Deficient Group

\section{DISCUSSION}

This cross-sectional study deals with a homogenous group of women with respect to age and menopausal status. All participants were screened for diseases known to influence bone metabolism. Low vitamin D status is associated with an increased risk of osteoporosis and a variety of other health outcomes and is an area that requires urgent attention. The exact role of other micronutrients on bone remains to be illdefined. Literature shows a clear link between vitamin D, nutrition, and skeletal integrity including fracture reduction. Osteoporosis is usually preventable public health pandemic. Some risk factors such as low calcium intake, vitamin D deficiency, and physical inactivity are amenable to early interventions that will help maximise peak bone density. Other risk factors subject to modification are cigarette smoking and excessive consumption of protein, caffeine, and alcohol. Hip fractures are the most serious outcome of osteoporosis with enormous personal and public health consequences.

In perimenopausal women, the risk of osteoporotic fracture and the use of hormone and vitamin D supplementation can be best estimated on the basis of bone mineral density as measured by dual energy $\mathrm{x}$-ray absorptiometry, clinical risk factors evident from the history and physical examination coupled with the presence or absence of existing fractures.[24]

In this group of healthy women after ten years of menopause, the vitamin D status is assessed by the measurements of vitamin D levels. The preferred range is 40$60 \mathrm{ng} / \mathrm{mL}$. Vitamin D intoxication occurs when the vitamin D level is $>150 \mathrm{ng} / \mathrm{mL}$. [25] Vitamin $\mathrm{D}$ is the most toxic of all vitamins. Like all fat-soluble vitamins, vitamin $\mathrm{D}$ can be stored in the body and is only slowly metabolised. High doses of more than 1,00,000 IU for weeks or months can cause loss of appetite, nausea, thirst, and stupor. Enhanced calcium absorption and bone resorption results in hypercalcaemia, which can lead to deposition of calcium in many organs, particularly the arteries and kidneys.
In adults, vitamin $\mathrm{D}$ deficiency induces secondary hyperparathyroidism, which causes a loss of matrix and minerals thus increasing the risk of osteoporosis and fractures. In addition, the poor mineralisation of newly laid down bone matrix in adult bone results in the painful bone disease of osteomalacia. Vitamin D deficiency causes muscle weakness increasing the risk of falling and fractures. Vitamin D deficiency also has other serious consequences on overall health and well-being.[26]

Osteoporosis is a major preventable public health problem. Some of risk factors such as low calcium intake, vitamin D deficiency, and physical inactivity are amenable to early interventions that will help maximise peak bone density. In our study, $79 \%$ were in the insufficient range, $21 \%$ were in the deficient range with normal levels of serum alkaline phosphatase, and none were in the optimal level. Study by Dennis T. Villareal et al in postmenopausal women had low vitamin $\mathrm{D}$ levels with higher serum alkaline phosphatase. Study of vitamin D level in postmenopausal women by Lars Rejnmark et al also showed lower levels of vitamin D. This study which was conducted in South Indian population adds evidence for the prevalence of vitamin D insufficiency and deficiency in elderly postmenopausal women, which increases the incidence of bone fractures and related comorbidities.

\section{Limitations}

The cross-sectional design of our study and the smaller sample size does not allow for causal conclusions and therefore the relationship between plasma levels of vitamin D and alkaline phosphatase should be evaluated further.

\section{CONCLUSION}

Vitamin D deficiency is finally being recognised as an epidemic for all age groups in most industrialised countries. Ninety to $95 \%$ of our vitamin D requirement comes from exposure to sunlight. Vitamin D deficiency and insufficiency are common in elderly South Indian population, which is not properly identified.

Vitamin D insufficiency and deficiency is unequivocally linked to several other common and morbid conditions. So, early detection and treatment of vitamin D deficiency will prevent mortality and morbidity in elderly. Serum vitamin D levels may not always be correlated with increased serum alkaline phosphatase levels.

\section{REFERENCES}

1. Matsuoka LY, Ide L, Wortsman J, et al. Sunscreen suppress cutaneous vitamin D3 synthesis. J Clin Endocrinol Metab 1987;64(6):1165-8.

2. Holick MF, Tian XQ, Allen M. Evolutionary importance for the membrane enhancement of the production of vitamin D3 in the skin of poikilothermic animals. Proc Natl Acad Sci USA 1995;92(8):3124-6.

3. Lanham-New SA, Thompson RL, More J, et al. Importance of vitamin D, calcium, and exercise to bone health with specific reference to children and adolescents. Nutr Bull 2007;32(4):364-77.

4. Kinyamu HK, Gallagher JC, Balhorn KE, et al. Serum vitamin D metabolites and calcium absorption in normal young and elderly free-living women and in women living in nursing homes. Am J Clin Nutr 1997;65(3): 790-7. 
5. Holick MF. Vitamin D: importance in the prevention of cancers, type 1 diabetes, heart disease, and osteoporosis. Am J Clin Nutr 2004;79(3):362-71.

6. Malabanan A, Veronikis IE, Holick MF. Redefining vitamin D insufficiency. Lancet 1998;351(9105):805-6.

7. McKenna MJ. Differences in vitamin D status between countries in young adults and the elderly. Am J Med 1992;93(1):69-77.

8. Tsai KS, Heath H, Kumar R, et al. Impaired vitamin D metabolism with ageing in women. Possible role in pathogenesis of senile osteoporosis. J Clin Invest 1984;73(6):1668-72.

9. Welten DC, Kemper HC, Post GB, et al. A meta-analysis of the effect of calcium intake on bone mass in young and middle-aged females and males. J Nutr 1995;125(11):2802-13.

10. Anderson JB. Calcium, phosphorus, and human bone development. J Nutr 1996;126(Suppl 4):S1153-S8.

11. Underwood JL, DeLuca HF. Vitamin D is not directly necessary for bone growth and mineralisation. Am J Physiol Endocrinol Metab 1984;246(6):E493-E8.

12. Boland R. Role of vitamin D in skeletal muscle function. Endocr Rev 1986;7(4):434-48.

13. Heaney RP, Dowell MS, Hale CA, et al. Calcium absorption varies within the reference range for serum 25hydroxyvitamin D. J Am Coll Nutr 2003;22(2):142-6.

14. Pearce SHS, Cheetham TD. Diagnosis and management of vitamin D deficiency. BMJ 2010;340:b5664.

15. Pittas AG, Lau J, Hu FB, et al. The role of vitamin D and calcium in type 2 diabetes. A systematic review and meta-analysis. J Clin Endocrinol Metab 2007;92(6): 2017-29.

16. Dobnig $\mathrm{H}$, Pilz S, Scharnagl $\mathrm{H}$, et al. Independent association of low serum 25-hydroxyvitamin D and 1,25dihydroxyvitamin $\mathrm{D}$ levels with all-cause and cardiovascular mortality. Arch Intern Med 2008;168(12):1340-9.
17. Wark JD. Osteoporotic fractures: background and prevention strategies. Maturitas 1996;23(2):193-207.

18. Bouillon R, Okamura WH, Norman AW. Structurefunction relationships in the vitamin D endocrine system. Endocrine Rev 1995;16(2):200-57.

19. Aaron JE, Gallagher JC, Anderson J, et al. Frequency of osteomalacia and osteoporosis in fractures of the proximal femur. Lancet 1974;1(7851):229-33.

20. Lips P. Vitamin D deficiency and secondary hyperparathyroidism in the elderly: consequences for bone loss and fractures and therapeutic implications. Endocr Rev 2001;22(4):477-501.

21. Chapuy MC, Preziosi P, Maaner M, et al. Prevalence of vitamin $\mathrm{D}$ insufficiency in an adult normal population. Osteopor Int 1997;7(5):439-43.

22. Sievenpiper JL, McIntyre EA, Verrill $M$, et al. Unrecognised severe vitamin D deficiency. BMJ 2008;336(7657):1371-4.

23. Department of Health. Nutrition and bone health: With particular reference to calcium and vitamin D. Report of the subgroup on bone health, working group on the nutritional status of the population of the committee on medical aspects of the food nutrition policy. Rep Health Soc Subj 1998;49(3-17):1-24.

24. Barger-Lux MJ, Heaney RP, Dowell S, et al. Vitamin D and its major metabolites: serum levels after graded oral dosing in healthy men. Osteoporos Int 1998;8(3):222-30.

25. Holick MF. Vitamin D deficiency. $N$ Engl J Med 2007;357:266-81.

26. Bouillon R. Vitamin D: From photosynthesis, metabolism, and action to clinical applications. In: DeGroot LJ, Jameson JL, eds. Endocrinology. Philadelphia: Saunders WB 2001:1009-28. 